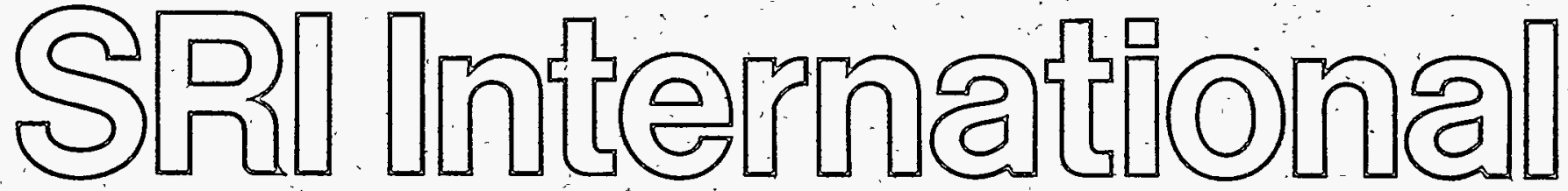

DoEPCP $91344--$ T18

Quarterly Technical Report \#16 - June 1996

\section{ADVANCED SEPARATION TECHNOLOGY FOR FLUE GAS CLEANUP}

Abhoyjit S. Bhown

Arash Bahman

SRI International

333 Ravenswood Avenue

Menlo Park, CA 94025

SRI Project No. PYU-3501

Prepared for:

U.S. DEPARTMENT OF ENERGY

Pittsburgh Energy Technology Center

P.O. Box 10940

MS 921-118

Pittsburgh, PA 15236-0940

Attn: Document Control Center

DOE Contract No. DE-AC22-92PC91344
Kamalesh K. Sirkar

Sudipto Majumdar

Debabrata Bhaumick

New Jersey Institute of Technology

University Heights

Newark, NJ 07102 


\section{DISCLAIMER}

Portions of this document may be illegible in electronic image products. Images are produced from the best available original document. 


\section{DISCLAIMER}

This report was prepared as an account of work sponsored by an agency of the United States Government. Neither the United States Government nor any agency thereof, nor any of their employees, make any warranty, express or implied, or assumes any legal liability or responsibility for the accuracy, completeness, or usefulness of any information, apparatus, product, or process disclosed, or represents that its use would not infringe privately owned rights. Reference herein to any specific commercial product, process, or service by trade name, trademark, manufacturer, or otherwise does not necessarily constitute or imply its endorsement, recommendation, or favoring by the United States Government or any agency thereof. The views and opinions of authors expressed herein do not necessarily state or reflect those of the United States Government or any agency thereof. 


\section{CONTENTS}

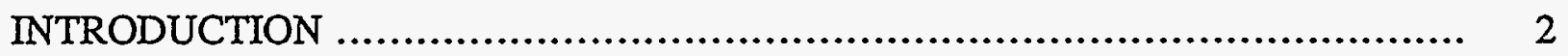

SUMMARY OF QUARTERLY PROGRESS …..................................... 4

TASK 9: PERFORMANCE OF SCALABLE MODULES........................... 5

\section{FIGURES}

1. Sherwood Number vs. Reynolds Number (water) $\ldots \ldots \ldots \ldots \ldots \ldots \ldots \ldots \ldots \ldots \ldots . \ldots \ldots$

\section{TABLES}

1. Flow Rate Distribution in Four-Unit Welded Module.............................. 3

2. Physical Properties of d-DMA......................................................... 6

$3 \quad$ Physical Properties of d-DMA....................................................... 8 


\section{INTRODUCTION}

The objective of this work is to develop a novel system for regenerable $\mathrm{SO}_{2}$ and $\mathrm{NO}_{\mathrm{x}}$ scrubbing of flue gas that focuses on (a) a novel method for regeneration of spent $\mathrm{SO}_{2}$ scrubbing liquor and (b) novel chemistry for reversible absorption of $\mathrm{NO}_{\mathrm{x}}$. In addition, high efficiency hollow fiber contactors (HFC) are proposed as the devices for scrubbing the $\mathrm{SO}_{2}$ and $\mathrm{NO}_{\mathrm{x}}$ from the flue gas. The system will be designed to remove more than $95 \%$ of the $\mathrm{SO}_{\mathrm{x}}$ and more than $75 \%$ of the $\mathrm{NO}_{\mathrm{x}}$ from flue gases typical of pulverized coal-fired power plants at a cost that is at least $20 \%$ less than combined wet limestone scrubbing of $\mathrm{SO}_{\mathbf{x}}$ and selective catalytic reduction of $\mathrm{NO}_{\mathbf{x}}$. In addition, the process will make only marketable byproducts, if any (no waste streams).

The major cost item in existing technology is capital investment. Therefore, our approach is to reduce the capital cost by using high efficiency hollow fiber devices for absorbing and desorbing the $\mathrm{SO}_{2}$ and $\mathrm{NO}_{\mathrm{x}}$. We will also introduce new process chemistry to minimize traditionally wellknown problems with $\mathrm{SO}_{2}$ and $\mathrm{NO}_{x}$ absorption and desorption. For example, we will extract the $\mathrm{SO}_{2}$ from the aqueous scrubbing liquor into an oligomer of dimethylaniline to avoid the problem of organic liquid losses in the regeneration of the organic liquid. Our novel chemistry for scrubbing $\mathrm{NO}_{\mathrm{x}}$ will consist of water soluble phthalocyanine compounds invented by SRI and also of polymeric forms of $\mathrm{Fe}^{++}$complexes similar to traditional $\mathrm{NO}_{\mathrm{x}}$ scrubbing media described in the open literature. Our past work with the phthalocyanine compounds, used as sensors for $\mathrm{NO}$ and $\mathrm{NO}_{2}$ in flue gases, shows that these compounds bind $\mathrm{NO}$ and $\mathrm{NO}_{2}$ reversibly and with no interference from $\mathrm{O}_{2}, \mathrm{CO}_{2}, \mathrm{SO}_{2}$, or other components of flue gas.

The final novelty of our approach is the arrangement of the absorbers in cassette (stackable) form so that the $\mathrm{NO}_{\mathrm{x}}$ absorber can be on top of the $\mathrm{SO}_{\mathrm{x}}$ absorber. This arrangement is possible only because of the high efficiency of the hollow fiber scrubbing devices, as indicated by our preliminary laboratory data. This cassette (stacked) arrangement makes it possible for the $\mathrm{SO}_{2}$ and $\mathrm{NO}_{x}$ scrubbing chambers to be separate without incurring the large ducting and gas pressure drop costs necessary if a second conventional absorber:vessel were used. Because we have separate scrubbers, we will have separate liquor loops and deconyolute the chemical complexity of simultaneous $\mathrm{SO}_{2} / \mathrm{NO}_{x}$ scrubbing.

We will conduct our work in a 60-month period (5/92 to 4/97), encompassing 16 tasks (Table 1), beginning with studies of the fundamental chemistry and of the mass transfer characteristics of small HFC modules in the laboratory. We will then examine the most favorable method of $\mathrm{SO}_{2}$ liquor regeneration, determine the ability of the HFC devices to withstand particulate matter, 
and examine the behavior of scalable modules. In the final 15 months of the program, we will determine the fundamental mass transfer behavior of a subscale prototype system. Based on these data, a computational design model will be devised to guide further scaleup efforts that may follow.

Table 1

PROJECT TASKS AND SCHEDULE

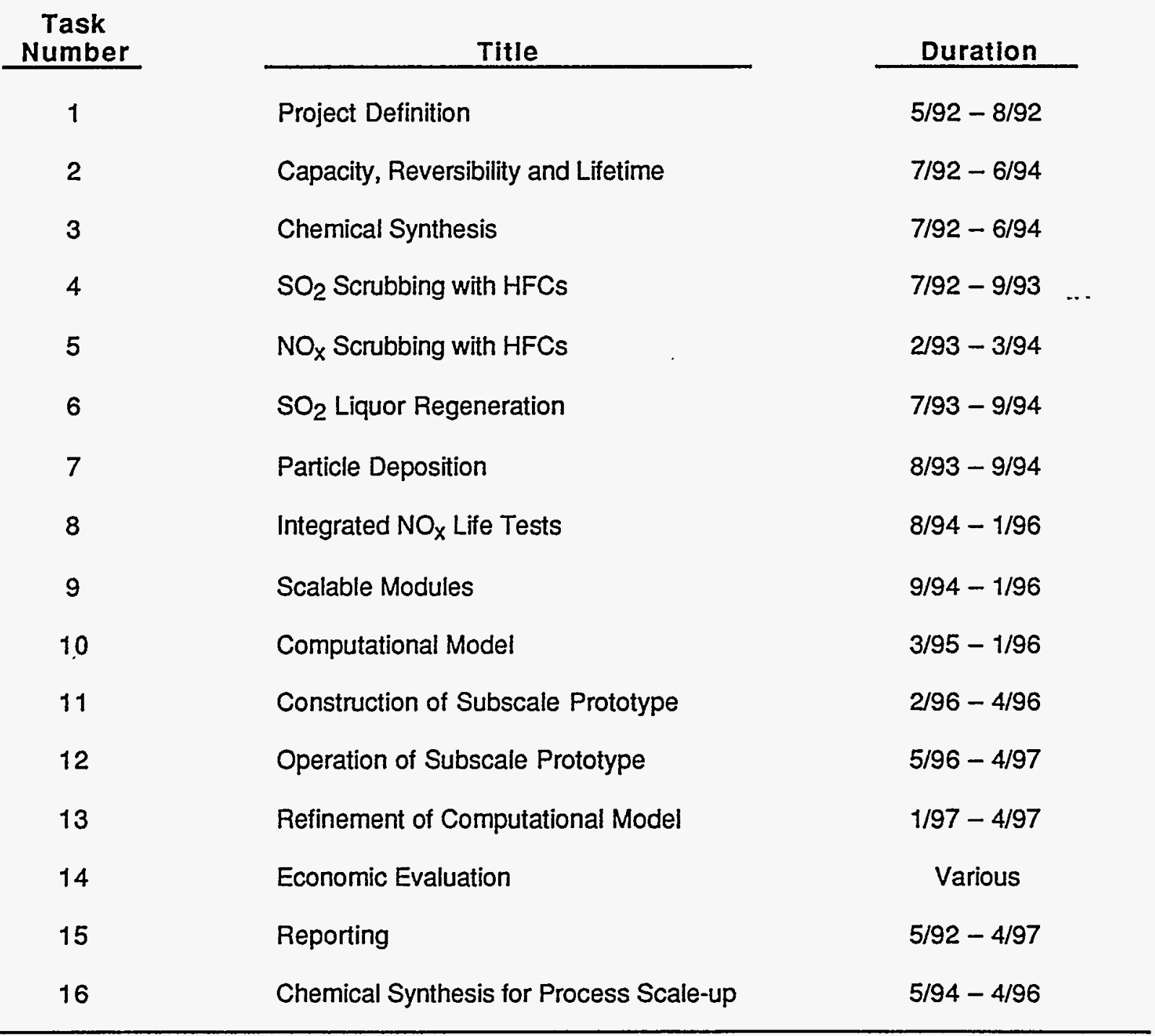




\section{SUMMARY OF QUARTERLY PROGRESS}

During the first quarter of 1996, we continued work on Task 9. 


\section{TASK 9: PERFORMANCE OF SCALABLE MODULES}

Because of the need for billions of (approximately 30-cm long) fibers to treat the flue gas from a $500 \mathrm{MW}$ (e) plant, it is critical to establish the mass transfer characteristics of a module that can be scaled up to a prototypical size. To appreciate this point, one must recognize that approximately 250,000 modules of 2 " diameter would be required to provide one billion fibers. Such an arrangement would provide a ducting, plumbing, and maintenance nightmare in a full-scale plant and clearly would not be economical or workable. A new design concept, such as rectangular modules, is needed for a full-scale plant. Therefore, the objective of Task 9 is to develop the mass transfer fundamentals of rectangular modules.

In the previous quarter (Quarterly Technical Report \#15), we reported that the four-unit welded hollow fiber contactor was sent back to Setec for repairs. The following is a summary of the changes that were made to the module.

The leak we had observed in one of the submodules was repaired. The porex at the inlet, which had begun to appear soiled, was replaced with clean material. The new porex is shaped circular rather than square in an attempt to create a better seal. In addition, we were given removable orifices in diameters of $1 / 16$ " and $3 / 32$ " to enable us to distribute the flow more evenly among the submodules.

The module was not returned to us until late January, at which time it was necessary to spend several days drying the pores. We also determined the best configuration of the inlet orifices to obtain a good flow distribution. We chose to use no orifice on the first two submodules, a $3 / 32$ " orifice on submodule 3 and a $1 / 16$ " orifice on submodule 4 . The distribution (shown in Table 2), although not perfectly even, is much better than previously reported (see Quarterly Technical Report \#15). 
Table 2

FLOW RATE DISTRIBUTION IN FOUR-UNIT WELDED MODULE

\begin{tabular}{ccc}
$\begin{array}{c}\text { Submodule } \\
\text { No. }\end{array}$ & $\begin{array}{c}\text { Flow } \\
\text { (SLPM) }\end{array}$ \\
1 & 19.0 \\
2 & 18.2 \\
3 & 17.4 \\
4 & 24.8 \\
\hline
\end{tabular}

During this quarter, we performed $\mathrm{SO}_{2}$ scrubbing tests with the repaired four-unit welded module. We also prepared to begin combined $\mathrm{SO}_{2}$ absorption/scrubbing liquor regeneration, determined physical properties of the organic extractant, and performed one combined absorption/extraction experiment.

Figure 1 shows the results of the $\mathrm{SO}_{2}$ scrubbing experiments, in which we used water as the scrubbing liquid. The Reynolds vs. Sherwood plot is given for the repaired four-unit module along with the single unit module and the four-unit module before repairs. From this graph, we can see that the performance of the module has not changed after the repairs. At first, one may expect the mass transfer to improve with a better gas flow distribution, but since mass transfer is dominated by the liquid flow rate, a better gas flow distribution may not necessarily improve performance. Regardless, the four-unit module is still performing poorly when compared to the single unit module. We continue believe that this is due to poor liquid flow distribution. One possible means to improve flow distribution is to change the module mounting from vertically to horizontally. In earlier work performed at NJIT, the module orientation was found to have an impact on the mass transfer coefficient (see Figure 4-11, Topical Report, 1995). We intend to conduct these experiments next quarter.

We measured several physical properties of the organic $\mathrm{SO}_{2}$ extractant (d-DMA); these are shown in Table 3. We have chosen to use Batch 1 in our experiments because of its lower melting point and lower viscosity; if there is not enough d-DMA in Batch 1 then we will use Batch 2.

After completing all of the pump, rotameter, mass flow controller and orifice calibrations and testing the apparatus for leaks while pressurized at $15 \mathrm{psig}$, we began combined $\mathrm{SO}_{2}$ absorption/scrubbing liquor regeneration experiments. We used the welded single-unit module to scrub the flue gas with the aqueous sodium sulfite solution, and the welded four-unit module to 


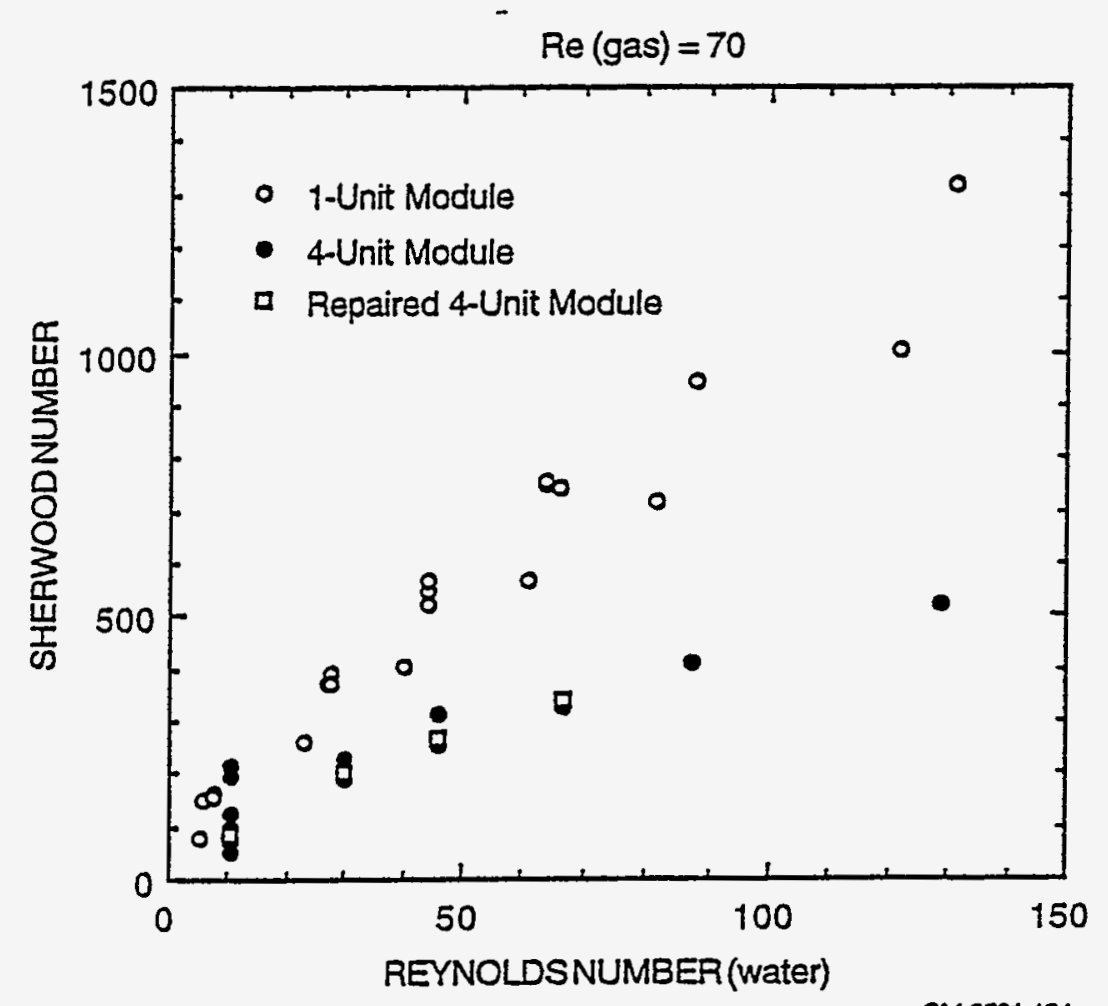

CM-3501-134

Figure 1. Sherwood Number vs. Reynolds Number (water). 
Table 3

PHYSICAL PROPERTIES OF d-DMA

\begin{tabular}{lccc}
\hline \multicolumn{1}{c}{$\begin{array}{c}\text { Property } \\
\text { Measured }\end{array}$} & $\begin{array}{c}\text { Batch 1 } \\
\text { (distilled 10/19/95) }\end{array}$ & \multicolumn{1}{c}{$\begin{array}{c}\text { Batch 2 } \\
\text { (distilled 10/25/95) }\end{array}$} \\
$\begin{array}{l}\text { Melting Temperature } \\
\text { Range }\end{array}$ & $29.5-31^{\circ} \mathrm{C}$ & & $39-44^{\circ} \mathrm{C}$ \\
Density at $59^{\circ} \mathrm{C}$ & & \\
Viscosity at $39^{\circ} \mathrm{C}$ & $0.990 \mathrm{~g} / \mathrm{mL}$ & & $1.001 \mathrm{~g} / \mathrm{mL}$ \\
Viscosity at $59^{\circ} \mathrm{C}$ & $17.7 \mathrm{cP}$ & $23.2 \mathrm{cP}$ \\
\hline
\end{tabular}

contact the aqueous solution and the organic extractant (see Quarterly Technical Report \#14 for the process flow diagram).

We were able to run the process for about two hours, but did not reach steady-state. Initially, $\mathrm{SO}_{2}$ removals were high ( $\left.>99 \%\right)$ but then began to decline gradually. The behavior was expected, as we anticipate the desorption of the d-DMA to be the limiting factor. Removal rates will continue to decrease as the d-DMA becomes closer to saturation with $\mathrm{SO}_{2}$.

During the experiment, we observed the sodium sulfite solution turning an orange color; . we suspect that the solution is extracting an impurity in the d-DMA that is soluble in water/sodium sulfite. We plan to analyze the material to determine its chemical structure. We do not expect the impurity to cause problems in the process, however, when we shut down between tests we will always replace the sodium sulfite with fresh solution.

The major obstacle we face right now stems from the higher melting point of the d-DMA. After running the experiment, we flushed the contactor with methanol but still noticed a brown hue inside the module. We used a better solvent, trichloroethylene, which removed most traces of $d$ DMA. Because the solvent cleaning and vacuum drying process was so time consuming, it is not conceivable to clean the module between runs. Instead, we will keep it heated in an oven to prevent the d-DMA from solidifying. This technique may increase the likelihood of emulsions forming during experiments; however, we do not anticipate this to cause any major problems.

The experiment we performed this quarter indicated that it will probably take several days to reach steady state conditions. Therefore, our efforts are now focused on improving the integrity of the system in order to allow for longer periods of continuous operation. 